Disorders in Childhood, Adolescence and Adulthood. Dtsch Ärztebl Int. 2012;109(48):821288. doi:10.3238/arztebl.2012.0821

7. Hashemiyoon R, Kuhn J, Visser-Vandewalle V. Putting the Pieces Together in Gilles de la Tourette Syndrome: Exploring the Link Between Clinical Observations and the Biological Basis of
Dysfunction. Brain Topogr. 2017;30(1):3-29. doi:10.1007/s10548-016-0525-z

8. Chee KY, Sachdev $\mathbf{P}$. The clinical features of Tourette's disorder: an Australian study using a structured interview schedule. Aust $\mathrm{N} Z$ J Psychiatry. $1994 ; 28(2): 313-318$. doi:10.1080/00048679409075645

\title{
KẾT QUẢ LÂM SÀNG CỦA CÁC TRƯỜNG HỢP CHUYỂN Mô̂T PHÔI NANG QUA PHƯƠ'NG PHÁP NUÔI CẤY TIME LAPSE TẠI TRUNG TÂM HỖ TRỢ SINH SẢN VINMEC TIMES CITY
}

\author{
Diêm Thị Yến*, Lê Thị Phương Lan*, Nguyễn Thị Cẩm Vân* \\ Nguyễn Thị Như Trang*, Trần Huệ Trân*, Trương Văn Hạnh*, \\ Khuất Hữu Quân*, Nguyễn Vũ Hà*, Vũ Văn Thành*, Vũ Thị Liên*
}

\section{TÓM TẮT}

Mục tiêu: Phân tích mối liên quan giữa các bất thường xuất hiện trong quá trình phân chia của phôi giai đoạn sớm và kết quả lâm sàng. Đối tượng và phương pháp nghiên cứu: Nghiên cứu tiến hành trên 88 trường hợp chuyển 1 phôi nang trong chu kỳ chuyển phôi đông lanh, các phôi được tao ra từ chu kỳ thụ tinh ống nghiệm và nuôi cấy phôi bằng hệ thống timelapse. Các bệnh nhân sẽ được đánh giá kết quả có thai bằng xét nghiệm ßhcg vào ngày 14 sau chuyển phôi và siêu âm theo dõi đến thai diễn tiến, sau 10 tuần. Kết quả: tỷ lệ $\beta$ hcg $(+)$, thai lâm sàng, thai diễn tiến lần lướt là $62,5 \%, 55,7 \%, 51,1 \%$. Trong đó, tỷ lệ có thai của nhóm không xuất hiện bất thường trong phân chia giai đoạn đâu cao hơn so với nhóm bất thường ở cả 2 lần phân chia đâuu tiên, về tỷ lệ ßhcg $(+)(67 \%$ so với $51 \%)$, tỷ lê thai lâm sàng $(61 \%$ so với $41 \%$ ) và tỷ lệ thai diển tiến (56\% so với $37 \%$ ), tuy nhiên sự khác biệt không có ý nghĩa thống kê. Không ghi nhận trường hợp có thai nào khi chuyển các phôi có hình thành khổng bào trong phôi bào giai đoạn phôi dâu. Kết luận: những phôi không xuất hiện bất thường trong những lần phân chia đầu tiên của phôi sẽ mang lại kết quả có thai tốt hơn so với những phôi có bất thường xuất hiện 2 lần. Tuy nhiên, cần thực hiện nghiên cứu với cõ mẫu lớn hơn để thu được kết quả có độ tin cậy cao hơn.

\section{SUMMARY}

THE CLINICAL OUTCOME OF ONE BLASTOCYST TRANSFER THROUGH TIMELAPSE TECHNIQUE AT ART CENTER, VINMECTIMES CITY HOSPITAL

Objective: Analysis of the association between abnormal morphokinetics of early embryos and clinical outcomes. Materials and Methods: the study

*Tt hỗ trợ sinh sản, Bệnh viện Vinmec Times City Chịu trách nhiệm chính:

Email: drdiemyen@gmail.com

Ngày nhân bài: 25.10.2021

Ngày phản biện khoa học: 21.12.2021

Ngày duyệt bài: 28.12.2021 conducted on 88 frozen embryo transfer cycles, with only 1 blastocyst. Blastocysts were made from ICSI cycles and cultured by timelapse system. Patients were evaluated for pregnancy outcomes by $\beta$ hcg testing on day 14 post-embryo transfer and follow-up ultrasound until the ongoing pregnancy, at 10 weeks. Results: the $\beta$ hcg $(+)$ rate, the clinical pregnancy rate, the ongoing pregnancy rate were $62,5 \%, 55,7 \%$, $51,1 \%$ respectively. The pregnancy rate of the group without abnormality in division were higher than that in the group with abnormality at 2 stages of division, the $\beta$ hcg $(+)$ rate $(67 \%$ vs $51 \%)$, the clinical pregnancy rate $(61 \%$ vs $41 \%)$, and the ongoing rate ( $56 \%$ vs $37 \%$ ), the difference is no significant. There was no case of pregnancy after embryo transfer with vaculation in blasomere. Conclusion: embryos that did not appear abnormal division during the early stage of development will have a better pregnancy outcome than embryos with abnormalities present twice. However, studies with larger sample sizes are needed to obtain more reliable results.

\section{I. ĐĂTT VẤN ĐỀ}

Hiện nay, ngành Hỗ trợ sinh sản đã có nhiều bước tiến vượt bậc, các kỹ thuật và máy móc hiện đại ra đời giúp nâng cao kết quả của một chu kỳ thụ tinh ống nghiệm. Một trong số đó phải kể đển phương pháp nuôi cấy phôi bằng hệ thống tủ nuôi cây theo dõi liên tục (timelapse). So sánh với phương pháp nuôi cấy phôi truyền thống, khi các tủ nuôi cấy phôi không gắn camera theo dõi, việc đánh giá chất lượng hình thái và tốc độ phát triển chỉ được tiến hành ở một thời gian cố định cụ thể trong ngày bởi các chuyên viên phôi học. Việc lấy các đĩa nuôi cấy ra khỏi tủ nuôi cấy để chụp ảnh có thể ảnh hưởng đến sự phát triển của phôi do tác động trực tiếp và điều kiện nuôi cấy. Với việc áp dụng tủ nuôi cấy timelapse, các hoạt động phân chia của phôi sẽ được ghi laai liên tục, qua đó, có thể phát hiện được các bất thường xuất hiện trong 
quá trình phôi phân chia, mà phương pháp nuôi cấy thông thường không phát hiện được. Các hiện tượng bất thường xuất hiện trong quá trình phát triển của phôi như: phân chia trực tiếp, phân chia ngược, phôi bào đa nhân, phân chia hỗn loạn, hình thành không bào trong phôi bào. Có những bất thường khi xuất hiện sẽ làm phôi dừng phát triển, nhưng có những bất thường mặc dù xuất hiện giai đoạn rất sớm nhưng phôi vẫn phát triển và tạo phôi nang. Vì thế, nếu không áp dụng hệ thống tủ time lapse, chúng ta có thể không phát hiện được những bất thường này, và các phôi nang có thể vẫn được lựa chọn để chuyển phôi. Vậy, câu hỏi đặt ra là, loại bất thường nào có ảnh hưởng trực tiếp đến khả năng làm tổ của phôi?

Nghiên cứu này tiến hành với mục tiêu: Phân tích mối liên quan giữa các bất thường xuất hiện trong quá trình phân chia của phôi giai đoạn sớm và kết quả lâm sàng khi chuyển 1 phôi nang.

\section{II. ĐỐI TƯợNG VÀ PHƯƠNG PHÁP NGHIÊN CứU}

Nghiên cứu hồi cứu trên 88 bệnh nhân làm thụ tinh ống nghiệm tại Trung tâm hỗ trợ sinh sản Vinmec Times City, thời gian từ 1/2021 $11 / 2021$.

Tất cả các bệnh nhân đều được làm thụ tinh ống nghiệm và nuôi cây phôi bằng hê thống Time-Lapse Geri 2.0, các bệnh nhân đều được chuyển phôi đông lạnh và chỉ chuyển 1 phôi nang.

Sau 14 ngày chuyển phôi, bệnh nhân được định lượng $\beta$ hcg để phát hiện có thai, theo dõi siêu âm tuần thứ 7 để phát hiện thai lâm sàng.

Phân tích số liệu bằng phần mềm SPSS 20.0

\section{KẾT QUẢ NGHIÊN CỨU}

\section{Bảng 1: Đăc điểm bênh nhân}

\begin{tabular}{|c|c|}
\hline Tuối trung bình & $31 \pm 4(22-43)$ \\
\hline Chuyến phôi D5 & $79 / 88(89,8 \%)$ \\
\hline Chuyển phôi D6 & $9 / 88(10,2 \%)$ \\
\hline Chất lượng phôi chuyển & \\
\hline Độ 1 & $61 / 88(69,3 \%)$ \\
\hline Độ 2 & $20 / 88(22,7 \%)$ \\
\hline Độ 3 & $7 / 88(8 \%)$ \\
\hline Độ 4 & $0 / 88$ \\
\hline Tý lệ $\beta$ HCG + & $55 / 88(62,5 \%)$ \\
\hline Tỷ lệ thai LS & $49 / 88(55,7 \%)$ \\
\hline Tỷ lề thai diên tiến & $45 / 88(51,1 \%)$ \\
\hline
\end{tabular}

Bảng 2: Mối liên quan giữa sự xuât hiện của phân chia bât thường ở các lân phân bào đâu tiến và tỷ lệ có thai

\begin{tabular}{|c|c|c|c|c|}
\hline & $\begin{array}{c}\text { Không bất } \\
\text { thường }\end{array}$ & $\begin{array}{c}\text { Bất thường lân phân chia } \\
\text { đâuu tiến hoặc lần 2 }\end{array}$ & $\begin{array}{c}\text { Bất thường cả 2 } \\
\text { lấn }\end{array}$ & $\mathbf{p}$ \\
\hline \multirow{2}{*}{$\boldsymbol{\beta}$ HCG + } & $24 / 36$ & $17 / 25$ & $14 / 27$ & $>0.05$ \\
\cline { 2 - 5 } & $67 \%$ & $68 \%$ & $51 \%$ & \\
\hline \multirow{2}{*}{ Thai lâm sàng } & $22 / 36$ & $16 / 25$ & $11 / 27$ & $>0.05$ \\
\cline { 2 - 5 } Thai diến tiến & $61 \%$ & $64 \%$ & $41 \%$ & \\
\hline
\end{tabular}

Nhận xét: tỷ lệ có thai của nhóm không xuất hiện bất thường phân chia tương đơng với nhóm có bất thường ở 1 lần phân chia. Tỷ lệ có thai của nhóm có bất hường ở 1 lần phân chia cao hơn so với nhóm bất thường ở cả 2 lần phân chia đâuu tiên, sự khác biệt không có ý nghĩa thống kê.

Bảng 3: Mối liến quan giữa các loại bất thường với tỷ lệ có thai

\begin{tabular}{|c|c|c|c|c|c|c|c|c|}
\hline & MulPN1 & Direct 1 & Reverse1 & MulPN2 & Direct 2 & Reverse 2 & Vac \\
\hline \multirow{4}{*}{$\begin{array}{c}\beta \text { HCG } \\
+\end{array}$} & Không có & 8 & 4 & 11 & 4 & 6 & 8 & 3 \\
\hline & thai & $30.8 \%$ & $36.4 \%$ & $39.3 \%$ & $36.40 \%$ & $50.0 \%$ & $50.0 \%$ & $100.0 \%$ \\
\hline & có & 18 & 7 & 17 & 7 & 6 & 8 & 0 \\
\hline & thai & $69.2 \%$ & $63.6 \%$ & $60.70 \%$ & $63.6 \%$ & $50.0 \%$ & $50.0 \%$ & $0.0 \%$ \\
\hline \multirow{4}{*}{$\begin{array}{l}\text { Thai } \\
\text { lâm } \\
\text { sàng }\end{array}$} & Không có & 9 & 6 & 15 & 5 & 8 & 10 & 3 \\
\hline & thai & $34.6 \%$ & $54.5 \%$ & $53.6 \%$ & $45.5 \%$ & $66.70 \%$ & $62.5 \%$ & $100.00 \%$ \\
\hline & Có & 17 & 5 & 13 & 6 & 4 & 6 & 0 \\
\hline & thai & $65.4 \%$ & $45.5 \%$ & $46.4 \%$ & $54.5 \%$ & $33.3 \%$ & $37.5 \%$ & $0.0 \%$ \\
\hline \multirow{4}{*}{$\begin{array}{l}\text { Thai } \\
\text { diê̂́n } \\
\text { tiến }\end{array}$} & Không có & 10 & 7 & 16 & 6 & 8 & 10 & 3 \\
\hline & thai & $23.3 \%$ & $63.6 \%$ & $57.10 \%$ & $54.5 \%$ & $66.7 \%$ & $62.5 \%$ & $100.0 \%$ \\
\hline & Có & 16 & 4 & 12 & 5 & 4 & 6 & 0 \\
\hline & thai & $61.5 \%$ & $36.4 \%$ & $42.9 \%$ & $45.5 \%$ & $33.3 \%$ & $37.5 \%$ & $0.0 \%$ \\
\hline
\end{tabular}

Chú thích: MulPN1: phôi bào đa nhân xuất hiện ở lần phân chia đầu tiên. Direct 1: hiện tượng phân chia trực tiếp xuất hiện ở lần phẩn

bào đầu tiên. Reverse1: hiện tượng phân chia ngược xuất hiện ở lần phân bào đầu tiên. Direct 2: hiện tượng phân chia trực tiếp xuất hiện ở lần 
phân bào thứ 2. Reverse2: hiện tượng phân chia ngược xuất hiện ở lần phân bào thứ 2 . Vac (vaculation): hiện tượng không bào hình thành trong phôi bào.

Nhận xét: tỷ lệ có thai ở các nhóm có phân chia trực tiếp và phân chia ngược ở lần phân chia thứ 2 thì tỷ lệ có thai thấp hơn so với các nhóm còn lại, tuy nhiên sự khác biệt không có ý nghĩa thống kê. Không ghi nhận trường hợp nào có thai khi xuất hiện không bào hình thành từ giai đoạn những lần phân chia đầu tiên và còn tồn tại kéo dài đến giai đoạn tạo phôi nang.

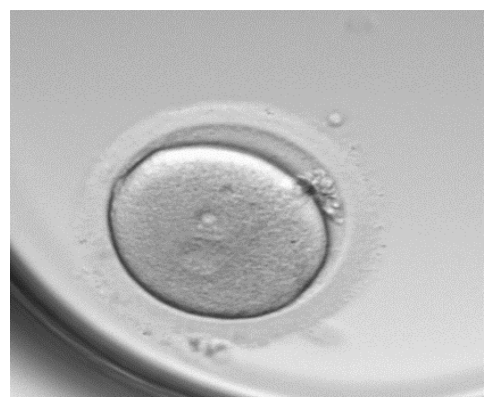

Trứng bệnh nhân P.H.HẠNH sau ICSI 26 giờ, xuất hiện 2 tiền nhân là dấu hiệu đã thụ tinh.

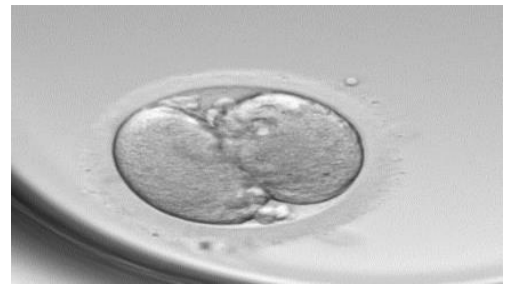

Phôi bệnh nhân P.H.HANH sau ICSI 30 giờ. Trứng bắt đâu lần phân chia đâu tiên tạo 2 tế bào, kích thường tương đối đồng đều, tỷ lệ mảnh võ̃ bào tương 5\%.

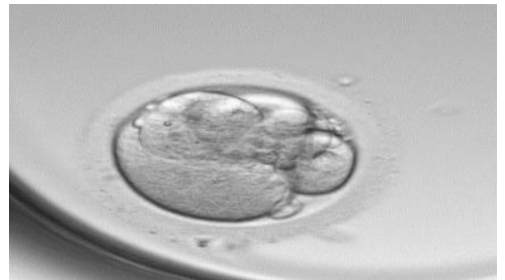

Phôi bệnh nhân P.H.HANH sau ICSI 32,5 giờ. Phôi bắt đâu lần phân bào thứ 2, trong đó có 1 tế bào phân chia trực tiếp thành 3 tế bào con và kích thước không đông đều nhau.

Hình 1: Hiện tượng phân chia trực tiếp
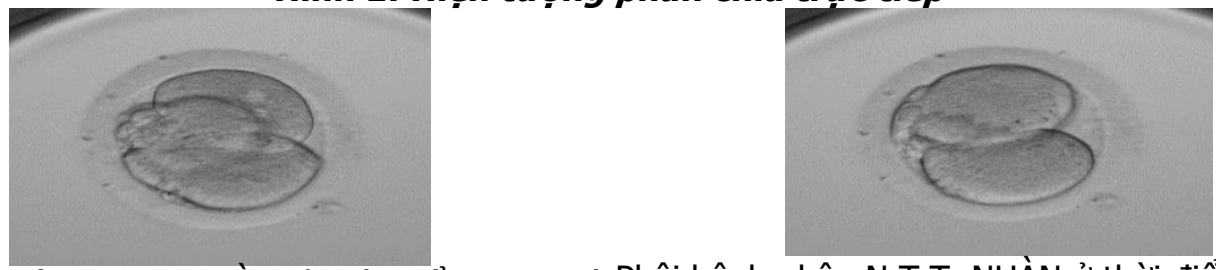

Phôi bênh nhân N.T.T. NHÀN ở thời điểm 26,5 giờ Phôi bệnh nhân N.T.T. NHÀN ở thời điểm 30,5 giờ sau ICSI. Sau lần phân chia đầu tiên, từ 1 trứng sau ICSI. Sau lần phân chia thứ 2, hai phôi bào có tạo ra phôi có 3 tế bào kích thước tương đối đồng hiện tượng hòa lại với nhau tạo thành 1 . Kết quả đều nhau, tỷ lệ mảnh võ bào tương là $5 \%$. rạo ra phôi có 2 tế bào từ phôi có 3 tế bào trước đó.

Hình 2: Hiện tượng phân chia ngược

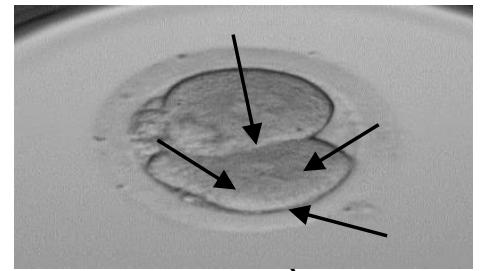

Phôi bệnh nhân N.T.T.NHÀN. Đầu mũi tên chỉ vào 4 nhân xuất hiện trong 1 phôi bào.

Hinh 3: Hiện tượng phôi bào đa nhân

\section{BÀN LUẬN}

Hiệu quả của một chu kỳ thụ tinh ống nghiệm phụ thuộc rất nhiều vào tuổi mẹ (5). Đặc biệt đã có nhiều nghiên cứu chỉ ra rắng, tuối mẹ cao (>35 tuổi) có ảnh hưởng vừa đến sự phát triển của phôi và ảnh hưởng lớn đến hiện tượng phôi lệch bội $(2,3)$. Theo Capalbo và cộng sự (2017), tỷ lệ phôi nang lệch bội ở nhóm phụ nữ dưới 35 tuổi là $30 \%$, thấp hơn có ý nghĩa khi so sánh với nhóm trên 44 tuổi là trên $90 \%$, vì vậy, độ tuổi được khuyến khích để tạo phôi là dưới 35 tuổi. ở

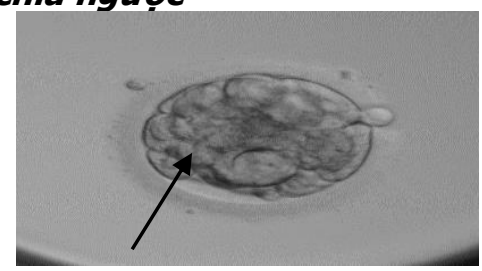

Đầu mũi tên chỉ vào không bào lớn xuất hiện trong phôi bào ở giai đoạn phôi dâu.

Hình 4: Hiện tượng không bào xuất hiện.

trong nghiên cứu này, độ tuổi trung bình của bệnh nhân là 31 tuổi, là độ tuổi thích hợp để tạo phôi, và từ đó hạn chế tác động của yểu tố tuổi lên sự phát triển của phôi (bảng 1).

Tất cả các bệnh nhân trong nghiên cứu đều được chuyển một phôi nang thay vì chuyển nhiều phôi, nhằm đánh giá chính xác sự phát triển và kết quả lâm sàng của phôi được chuyển. Trong đó, có $79 / 88(89,9 \%)$ trường hợp chuyển một phôi ngày nang ngày 5 và $9 / 88(10,2 \%)$ trường hợp chuyển một phôi nang ngày 6 . Khi 
đánh giá về chất lượng phôi chuyển, $92 \%$ phôi được chuyển có chất lượng tốt về mặt hình thái (độ 1 và độ 2). Các bệnh nhân được áp dụng chu kỳ chuyển phôi đông lạnh, sử dụng nội tiết thay thế, và niêm mạc thỏa mãn các điêu kiện cân thiết cơ bản cho chuyển phôi (độ dày >= $7 \mathrm{~mm}$, tưới máu tuýp II, hình thái 3 lá), tuổi mẹ phần lớn nằm trong độ tuổi thích hợp để mang thai, chất lượng phôi được chuyển là phôi tốt. Kết quả có thai của nghiên cứu đạt được là (bảng 1) tỷ lệ có xét nghiệm ßhcg dương tính là $55 / 88$ ca $(62,5 \%)$, và tỷ lệ thai lâm sàng $49 / 88$ $(55,7 \%)$ tỷ lệ này tương đương với các nghiên cứu chuyển một phôi nang trước đó của Nayar và cộng sự (2018) (4).

Với sự xuất hiện của timelapse trong những năm gần đây đã cung cấp thêm một công cụ mới cho việc nuôi cấy phôi cũng như các nghiên cứu về sự phát triển của phôi. Cụ thể là các hình ghi lại trên timelapse theo thời gian giúp ta quan sát được sự phát triển của phôi theo cả quá trình, thay vì đánh giá từng thời điểm riêng lẻ như ở phương pháp nuôi cây truyền thống. Từ các hình ảnh ghi nhận được trên timelapse, ta có thể phát hiện ra những hiện tượng bất thường trong quá trình phân chia của phôi ở những thời điểm khác nhau, mà có thể bị bỏ qua nếu chỉ áp dụng phương pháp đánh giá truyền thống, ở một thời điểm nhất định trong ngày. Do đó, có những phôi thậm trí có thể đạt loại 1 (loại tốt nhất) về mặt hình thái nhưng cũng có thể xuất hiện những bất thường trong quá trình phân chia, và các phôi này có thể được lựa chọn để chuyển. Đã có những nghiên cứu cho thấy rằng, các hiện tượng bất thường như phân chia ngược (hình 2), phân chia trực tiếp (hình 1 ), phôi bào đa nhân (hình 3), tao thành không bào (hình 4), có ảnh hưởng đến kết khả năng tạo phôi nang, tỷ lệ làm tổ, tỳ lệ phôi lệch bội (1). Theo kết quả của nghiên cứu này, tỷ lệ có thai của nhóm không có bất thường xuất hiên trong quá trình phân chia ở những lần phân chia đầu tiên là $67 \%$, cao tương đương so với nhóm có xuất hiện bất thường ở một lân phân chia là $68 \%$, và cao hơn so với nhóm có bất thường xuất hiên ở cả 2 lần phân chia là $51 \%$ (bảng 2). Tuy nhiên, sự khác biệt này là không có ý nghĩa thống kê, có thể do cỡ mẩu còn nhỏ. Qua đó, có thể nhận thấy rằng, các bất thường xuất hiện ở những lần phân chia đầu tiên của phôi có khả năng làm giảm tỷ lệ thành công của một chu kỳ thụ tinh ống nghiệm. Vậy, vấn đề cần đặt ra là loại bất thường nào sẽ thực sự có ý nghĩa quyết định đến khả năng làm tổ của phôi.
Khi phân tích cụ thể mối liên quan về tỷ lệ có thai và từng loại bất thường chúng tôi nhận thấy rằng, khi chuyển các phôi nang có hiện tượng phân chia trực tiếp hoặc phân chia ngược hoặc đa nhân xuất hiện ở lần phân bào thứ 2 cho tỷ lệ có thai thấp hơn hẳn so với những phôi nang có hiện tượng phân chia ngược hoặc phân chia trực tiểp hoặc đa nhân xuất hiện ở ngay lần phấn chia đâuu tiên. Tuy nhiên, sự khác biệt này là không có ý nghĩa thống kê, có thể do cỡ mẫu chưa đủ lớn. Với các phôi có xuất hiện không bào trong phôi bào ở những lần phân chia đầu tiên và còn tồn tại đến giai đoạn phôi dâu, thì không ghi nhận trường hợp nào có thai khi chuyển các phổi nang này (bảng 3 ). Điều này có thể giải thích được là do bản chất các không bào được hình thành trong phôi bào là dấu hiệu của quá trình tự tiêu của tế bào (hình 4), khi các không bào còn tồn tại và lớn dần là dấu hiệu báo trước của một sự chết tế bào, và do đó làm giảm tiềm năng làm tổ của phôi nang được chuyển.

\section{KẾT LUẬN}

Tủ nuôi cây times lapse là hệ thuống tủ nuôi cấy mang lại kết quả tạo phôi nang chất lượng tốt. Việc áp dụng phương pháp lựa chọn phôi dựa trên các hình ảnh ghi nhận được qua timeslapse giúp đưa ra lựa chọn có ý nghĩa cho ứng dụng lâm sàng. Từ các kết quả ghi nhận được có thể gợi ý rằng, những phôi không xuất hiện bất thường trong những lần phân chia đầu tiền của phôi sẽ mang lại kết quả có thai tốt hơn so với những phôi có bất thường xuất hiện 2 lần. Số lần bất thường phân chia xuất hiện càng nhiều ở các lần phân chia thì càng làm giảm tỷ lệ có thai. Với các trường hợp hình thành không bào trong phôi bào và tồn tại đến giai đoạn phôi dâu, không ghi nhận trường hợp nào có thai. Tuy nhiên, nghiên cứu còn hạn chế ở cõ̃ mẫu chưa đủ lớn, cần mở rộng nghiên cứu với cỡ mẫu lớn hơn để mang lại kết quả chính xác và tin cậy hơn.

\section{TÀI LIẸU THAM KHẢO}

1. Canto M. D., Coticchio G. , Renzini M. M., Ponti E. , Novara P.V., Brambillasca F. Cleavage kinetics analysis of human embryos predicts development to blastocyst and implantation. Reprod Biomed Online, 25 (2012), 474-480.

2. Capalbo A, Hoffmann ER, Cimadomo D, Maria Ubaldi F, Rienzi L. Human female meiosis revised: new insights into the mechanisms of chromosome segregation and aneuploidies from advanced genomics and time-lapse imaging. Hum Reprod Update (2017) 23(6).

3. Franasiak JM, Forman EJ, Hong KH, Werner MD, Upham KM, Treff NR, et al. The nature of 
aneuploidy with increasing age of the female partner: a review of 15,169 consecutive trophectoderm biopsies evaluated with comprehensive chromosomal screening. Fertil Steril (2014) 101:656-63.

4. Nayar K. D., Gahlot R., Kant G., Singh M., Sharma $\mathbf{N}$. Is time lapse a better option to improve clinical outcome over standard incubatora case controlled study. ASRM 2018.

5. Nelson SM, Lawlor DA. Predicting live birth, preterm delivery, and low birth weight in infants born from in vitro fertilisation: a prospective study of 144,018 treatment cycles. PLoS Med (2011) 8.

\title{
TÌNH TRANG SÂU RĂNG VÀ NHU CẦU ĐIỀU TRI Ở TRẺ 5, 12 TUỔI DÂN TộC THÁI Ở HUYỆN CON CUÔNG, TỈNH NGHỆ AN NĂM 2015
}

\author{
Vi Việt Cường ${ }^{1}$, Phạm Quốc Hùng ${ }^{2}$
}

\section{TÓM TẮT}

Nghiên cứu mô tả cắt ngang nhằm đánh giá tình trạng sâu răng ở trẻ 5, 12 tuổi dân tộc Thái tại huyện Con Cuông, tỉnh Nghê An. Nghiên cứu được hoàn thành vào tháng $5 / 2015$ với 473 trẻ 5 tuổi tại 9 trường mâm non và 476 trẻ 12 tuổi tai 9 trường trung hoc cơ sở ở huyện. Nghiên cứu theo phương pháp điều tra và phân loại của Tổ chức Y tế Thế giới (WHO) năm 2013; Kết quả nghiên cứu cho thấy: trẻ 5 tuổi: tỷ lệ sâu răng ở mức trung bình $(59,8 \%)$; nam $(62 \%)$ cao hơn nữ $(57,2 \%)$ với sự khác biệt không có ý nghĩa thống kê ( $p>0,05)$; Sâu-mất-trám răng ở mức độ trung bình $(2,71 \pm 3,22)$, trong đó chủ yếu là chỉ số sâu, chỉ số mất không có, chỉ số trám rất ít; Sâu-mất-trám mă̆t răng trung bình khá cao $(8,36 \pm 11,5)$; Nhu cầu điều trị: 0,52 răng/ 1 trẻ cân trám 1 mặt răng, 0,79 răng/ 1 trẻ cần trám 2 mă̆t răng. Trẻ 12 tuổi: tỷ lê sâu răng ở mức độ thấp $(14,3 \%)$; nam $(11,6 \%)$ thẩp hơn nữ $(16,9 \%)$ với sự khác biêt không có ý nghĩa thống kê $(p>0,05)$. Sâu-mất-trám răng ở mức độ rất thấp $(0,21 \pm 0,56)$ và Sâu-mất-trám măt răng ở mức rất thấp $(0,45 \pm 1,56)$. Nhu câu điều trị: 0,13 răng/1 trẻ cần trám 1 mặt răng; 0,04 răng/1 trẻ cần trám 2 mặt răng.

Ti̛ khóa: sâu răng, nhu cầu điều trị, trẻ năm tuổi, trẻ 12 tuổi

\section{SUMMARY}

\section{SITUATION OF TOOTH DECAY AND}

TREATMENT NEEDS IN THAI CHILDREN

AGED 5 AND 12 YEAR-OLD, IN CON CUONG DISTRICT, NGHE AN PROVINCE IN 2015

A cross-sectional descriptive study was implemented to assess tooth decay and treatment needs among children aged 5 and 12 year-old of Thai ethnic group in Con Cuong district, Nghe An province. The study was completed in May 2015 with 473 children aged 5-year-old in 9 preschools and 476 children aged 12-year-old in 9 middle schools in the

\footnotetext{
${ }^{1}$ Đại học Quốc tế Hồng Bàng,

${ }^{2}$ Trường Đại học Y Hà Nội

Chịu trách nhiệm chính: Vi Việt Cường

Email: vivietcuongdr05@gmail.com

Ngày nhận bài: 18.10.2021

Ngày phản biện khoa học: 16.12.2021

Ngày duyệt bài: 24.12.2021
}

district, according to the method of investigation and classification of WHO-2013; Research results showed that: 5-year-old children: the rate of tooth decay was average $(59.8 \%)$; male $(62 \%)$ higher than female $(57.2 \%)$ with the difference not statistically significant ( $p>0.05$ ); the average of tooth decay-loss-filling was at an middle level $(2.71 \pm 3.22)$, in which the index of decay was mainly, the index of loss was absent, the index of filling was very little; the average of decayloss-filling of tooth face was quite high $(8.36 \pm 11.5)$; treatment needs: 0.52 teeth/ 1 child need filling 1 tooth, and 0.79 teeth/ 1 child need filling 2 teeth. 12year-old children: the rate of tooth decay was low $(14.3 \%)$; male $(11.6 \%)$ lower than female $(16.9 \%)$ with the difference not statistically significant ( $p>0.05)$; the average of tooth decay-loss-filling was very low $(0.21 \pm 0.56)$, and the average of decay-lossfilling of tooth face was very low $(0.45 \pm 1.56)$; treatment needs: 0.13 teeth/ 1 child need filling 1 tooth, and 0.04 teeth 1 child need filling 2 teeth.

Keywords: tooth decay, treatment needs, fiveyear-old children, 12-year-old children

\section{I. ĐẶT VẤN ĐỀ}

Tình trạng sâu răng của trẻ em Việt Nam vẫn đang là vấn đề sức khỏe công cộng cần quan tâm, đặc biệt là vùng sâu vùng xa, đồng bào dân tộc thiểu số nơi gặp nhiều khó khăn trong chương trình chăm sóc sức khỏe răng miệng định hướng đến năm 2030 của Chính phủ [1]. Để có thêm dữ liệu làm cơ sở cho thiết kễ các chương trình can thiệp phòng chống sâu răng phù hợp cho từng khu vực và từng lứa tuổi khác nhau cần có thêm những nghiên cứu ở những nhóm dân cư đắc biêt là đồng bào các dân tộc thiểu số vùng sâu vùng xa. Nghiên cứu này được tiến hành nhằm đánh giá tình trạng sâu răng và nhu cầu điều trị của trẻ dân tộc Thái 5 tuổi tại các trường mầm non và trẻ dân tộc Thái 12 tuổi tại các trường trung học cơ sở thuộc 9 xã của huyện Con Cuông, tỉnh Nghệ An.

II. ĐỐI TƯỢNG VÀ PHƯƠNG PHÁP NGHIÊN CỨU

Đối tượng nghiên cứu: toàn bộ trẻ dân tộc Thái 5 tuổi ở 9 trường mầm non và 12 tuổi ở 9 